\title{
Building Information Modelling for Historical Building Historic Jeddah - Saudi Arabia
}

\author{
Ahmad Baik \\ Department of Civil, Environmental and Geomatic \\ Engineering \\ University College London UCL \\ London, United Kingdom \\ Abaik@kau.edu.sa
}

\author{
Jan Boehm \\ Department of Civil, Environmental and Geomatic \\ Engineering \\ University College London UCL \\ London, United Kingdom \\ J.boehm@ucl.ac.uk
}

\begin{abstract}
The topic of how the municipality of Jeddah can document, produce and preserve complete engineering information and drawings for historical buildings is one of the most important issues facing the Historic Jeddah district in the Kingdom of Saudi Arabia. The concept of using a remote collection of survey data with Architectural Photogrammetry and Terrestrial Laser Scanning has been accepted in several heritage locations worldwide. Additionally, the combination of the resulting information and Building Information Modelling has been developed as a technique to manage and document these historical buildings. In the last 20 years, several traditional approaches have been used to document, record, and survey heritage buildings in Historic Jeddah; however, these techniques have sometimes delivered unreliable information, taken a long time and inevitably omitted key details. This paper will focus on using Jeddah Historical Building Information Modelling; to produce complete engineering information and drawings.
\end{abstract}

\section{Keywords-Historical Jeddah, JHBIM, TLS, BIM}

\section{INTRODUCTION}

\section{A. Historical Jeddah Background}

The Saudi Arabian city of Jeddah, located in the western Hijaz region, has a long history and several heritage buildings dating from the 15th century "Fig.1". Jeddah is identified as the portal to Mecca and Medina, which are the two holy cities of Islam. The geographical features of Jeddah include a natural dock in the form of a curve, with a series of surrounding hills and mountains. Because of the coral reef surrounding the harbour, according to [1] "the coastal region is hard to navigate for ships and thus protected Jeddah from invasion in ancient times".

\section{B. Historic Jeddah issues}

How the municipality of Jeddah can save and preserve these heritage sites from the risk of erosion and collapse through either manmade and/or natural causes; e.g. fires, is one of the most important topics in Jeddah these days. Indeed, many of the historical buildings and houses in the Historic Jeddah district have been lost due to natural and human factors, and disasters such as fires.in the last three decades, and consequently, a huge basis of knowledge and key aspects of Historic Jeddah's past have gone. Today, a lot of historical buildings are deserted, often becoming a hiding place for criminals. According to many cultural heritage experts, these historical buildings need to be conserved, protected and re-used; otherwise, they will lose their essence of history and culture [2].
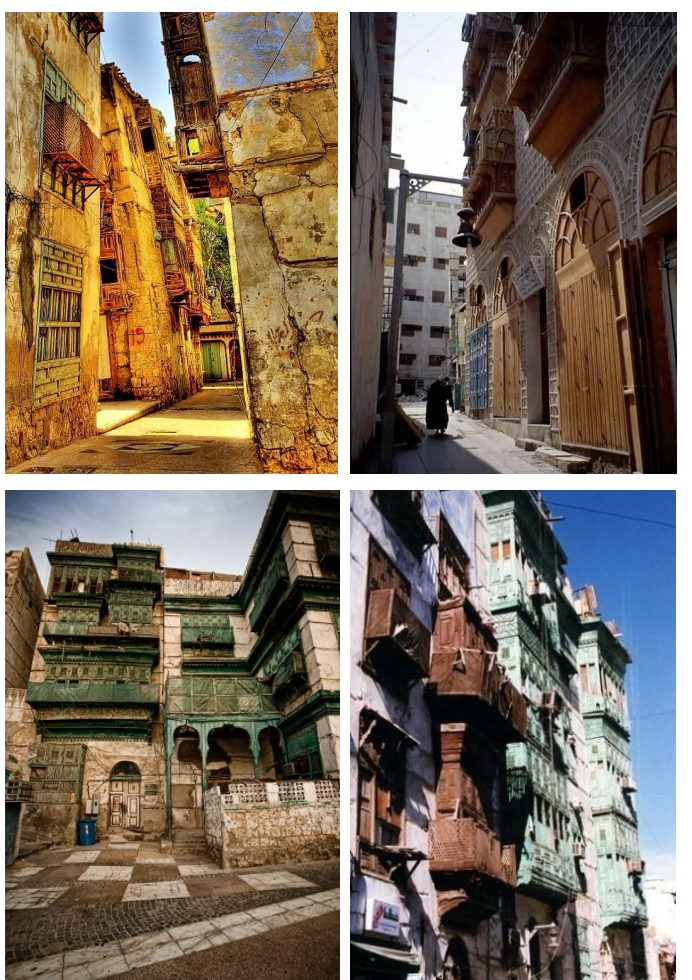

Fig. 1. Examples of the building in Historic Jeddah

\section{The Existing Solutions}

As a consequence of this issue regarding historical buildings in the Historic Jeddah district, the Jeddah municipality has been established in order to preserve and develop this district by using a method depending on engineering companies. However, this approach takes a long time to implement and sometimes delivers unreliable works.

The process of this method was initiated when the landlords of these historical buildings selected one of the engineering companies that were listed by the Jeddah 
municipality. For the second step, the company sent an engineering team that contained five groups to study the building, draw the outline and take pictures. The survey team used a range of survey equipment such as "Global Positioning System and Totals Stations" to get passible measurements of these historical houses [3]. Thereafter, the rest of the engineering groups focussed on accomplishing their fieldwork job; by writing, ccapturing images and drawing what could be detected on the site. In the final stage, the municipality of Jeddah received these documents and sent an inspector to examine the accuracy in order for them to make a decision about each particular building. In addition, the engineering companies also used traditional techniques and methods to do the job. To produce these documents and receive the final decision, the process could take around 10 months for a small building, and it needed even more time depending on the building size and the number of rooms. Moreover, according to [4], "this process costs a lot for both the municipality and for landlords".

\section{Aims}

Producing complete engineering information and drawings with the aid of the JHBIM can be achieved by using remote survey data via Terrestrial Laser Scanning combined with the images survey data. A number of applications and levels of remote managing will use the output information. Radwan Historical House was selected as a model for the task [2].

\section{E. Objectives}

1) Recording Historic Jeddah buildings as digital heritage documentation for several purposes, for example; constructional, structural and architectural purposes.

2) Creating a method, that can follow up the "running" of the historical buildings in Old Jeddah.

\section{LITERATURE REVIEW}

\section{A. Terrestrial Laser Scanning "TLS” and Digital Images}

About ten years ago, the technology of Terrestrial Laser Scanning became available in the engineering market and offered a new way of 3D data acquisition. Laser scanning technology has been developed in recent years, presenting new features such as inclination compensation, electronic levels, geo-referencing, and a digital camera [5]. The laser scanning features could be seen in traditional survey equipment such as total stations; but the features have been well developed recently, with a great number of brands of laser scanning systems in existence. It is hard to choose the most suitable laser scanning system; however many of these systems need to be improved and many are beta versions [5]. The most popular laser scanning brands are Faro, Trimble and Leica. Focusing on these technologies, it is noticeable how similar to each other they are, although they offer differences in accuracy, resolution, scanning distance, field of view, 3D scan precision, and scanning velocity. The Leica Scan Station C10 was used in this project. Furthermore, in the latest models of laser scanning the camera is integrated as a built in feature; these images can be colored within the point cloud data, which comes from the laser scanning. The image's RGB color data, according to [6] "can be used to sort data and by taking account of point translation, instrument rotation and perspective projection", moreover, "both camera and the laser must be correctly geometrically calibrated".

\section{B. Jeddah Historical Building Information "JHBIM"}

Our project is looking for a new advanced method to shift from conventional engineering works such as "CAD and 2D drawings, 2D constructive representation and $3 \mathrm{D}$ content models" towards the JHBIM [2]. This is in order to support preservation and to disseminate the knowledge of heritage and information sharing for expert users, organizations and experts concerned with governing procedure [7], [8]. As such, this project has begun since the explanation of the two dimensional Geographic Information System and traditional two dimensional representation methodologies to manage the historical building and on geo-spatial documents to manage the Cultural Heritage [9]. The Hijazi Architectural Objects Library "HAOL", which depends on the image survey and point cloud data, will be introduced, documented, and support any future projects in Historic Jeddah [10], [11]. The HAOL will be the last or the first stage of the JHBIM method, depending on the complexity of the site. Moreover, full engineering information and drawings will automatically be offered by the JHBIM. The heritage preservation domain can "deliver several things to the JHBIM such as the understanding of heritage buildings in Old Jeddah and the context, knowledge of materials, construction methods and building pathologies, understanding of heritage buildings in Old Jeddah with a wide range of materials and assemblies that are not documented and are not presented from stock libraries of 3D model parts" [2]. Furthermore, JHBIM can deliver several advantages to the historical preservation domain. For example, it allows for the complete study of planned restoration and modifications before final decisions are made; damage detection on surfaces; assisting in maintenance efforts; permitting a wider knowledge of public building as models can be consulted with as an open source, searching programs from remote positions and budgeting for repairs and maintenance. The JHBIM model allows remote examining inside and outside and offers better realization and management before the decision-making procedure of preservation projects has begun. In such a way, decision makers in the municipality of Old Jeddah can be more effective and efficient. According to [2] "By using the JHBIM method, we can reduce the delivery time of the project in "4 D", reduce the cost of "5 D", improve "6 D" lifecycle management, and perform reality with less delay and greater reliability than before. Additionally, several applications can be used for the output information over time, as and when needed". 


\section{SCAN TO JHBIM “METHOD”}

\section{A. Image survey and Laser survey data}

The JHBIM task started by collecting image survey data in order to capture the historical building's key characteristics. This step took more than three days. During this stage, images of the building were taken using a professional Canon 18 Mega Pixels camera. Indeed, the historical house has a huge number of Hijazi characters, such as the Mashrabiyahs and Roshans. Additionally, the image survey data could then be inputted into Architectural photogrammetric software using such programs as Autodesk Recap and PhotoModeler.

The second step of the JHBIM model began with the laser scanning survey of the Farsi house. A total of 8 scanstations worked for a week to finish this job. The scan-station positions were selected in such places where one could view the area and the targets of the laser scanning in "black/white", which produced a perfect, clear image. In order to achieve the greatest precision and to integrate the scan-stations, we used three marks as a minimum in common over these real-world stations. According to [12] "The selection of suitable viewpoint positions is very important for a successful survey of such monuments since the number of potential sensor stations is usually restricted by the complexity of the structure". These scan-stations have highly interfering parts impairing a successful incorporation. On the other hand, because of the height of the building and the stations' locations, we could not scan the roof of the Roshans and the House. The Leica C10 scan-station, which was used in the project, offered $7 \mathrm{~cm}$ resolution with a distance of $30 \mathrm{~m}$. Finally, the preparation steps initiate the scanning process; including "scan settings and targets registering", which takes around half an hour due to the large numbers of targets. In addition, the laser scanning takes around 15 minutes; and the image scanning takes a total of 20 minutes.

\section{B. Point Cloud Data Processing}

Creating point clouds model was done with the aid of a spatial program, such as the Autodesk Recap program, or Leica Cyclone software. Cyclone software was used in this project to create the point clouds model and to remove the unimportant data "noise". We spent more than three days completing this step. Next, the corresponding point clouds in the overlapping areas, which were the outcome of several scan-stations, were used for the registration process.

"Figure 2" shows the 3D points cloud for the Radwan House having been imported into the Autodesk Revit software.

\section{The JHBIM model}

There are several professional software programs, which can be used to handle the output of points cloud data. One common piece of software is the Autodesk Revit, which was used to build the model, due to its speed in building time, modifying the model into "3D", and its high level of flexibility and quality of construction documents.

"Figure 3" shows the JHBIM model through using Autodesk Revit. "Figure 4" shows Steps of the Roshan modelling.

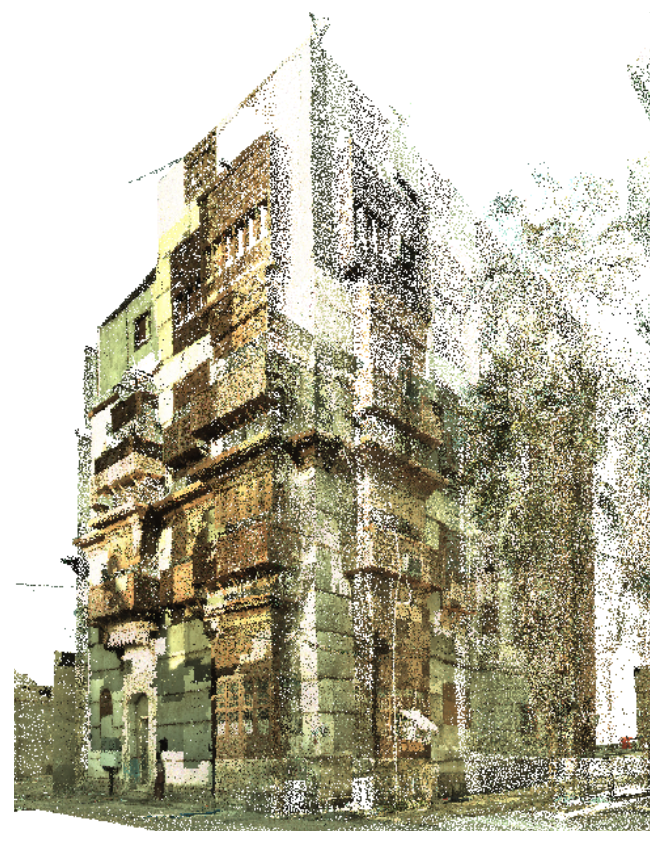

Fig. 2. 3D Point cloud model.

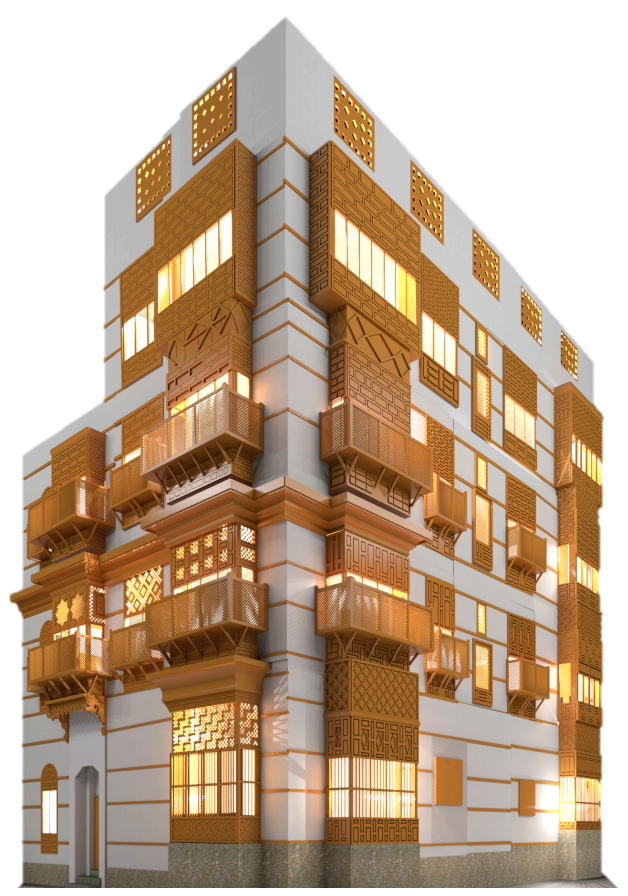

Fig. 3. 3D JH BIM model by Autodesk Revit. 


\section{CONCLUSION}

In the last two decades many methods have been used to preserve historical buildings in Old Jeddah; however, issues remain. The most suitable method to preserve Historic Jeddah can be established by involving the Building Information Modelling (BIM) method. With the resulting information, we can take the necessary action and determine which buildings need to be preserved, conserved, and which may have to be demolished. The Jeddah Historical BIM project should be expanded in the next few years to involve the rest of the Historic Jeddah district's buildings in order to form a complete heritage database. Furthermore, according to [2], the output material from Jeddah Historical BIM such as the floor plans, house damage situation, and preservation plans "can be collected in a database for spatial modelling and follow-up reasons such as security systems and fire systems to protect these sites from future damage". Additionally, the output data can be used for several other purposes over time, as needed.
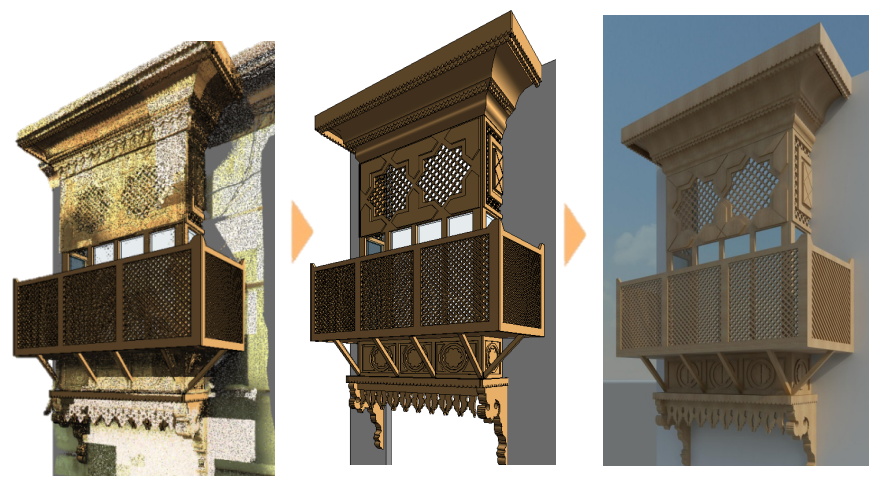

Fig. 4. Steps of the Roshan modelling.

\section{REFERENCES}

[1] A. Telmesani, F. Sarouji, and A. Adas, Old Jeddah A Traditional Arab Muslim City In Saudi Arabia, 1st ed. Jeddah: King Fahad national library, 2009.

[2] A. Baik, J. Boehm, and S. Robson, "Jeddah Historical Building Information Modeling 'JHBIM' Old Jeddah Saudi Arabia," ISPRS - Int. Arch. Photogramm. Remote Sens. Spat. Inf. Sci., vol. XL-5/W2, pp. 73-78, Jul. 2013.

[3] E. O. TYA, "Nasseef House Conservition," Jeddah, Saudi Arabia, 2007.

[4] S. Nawwar, "Jeddah Historic Preservation Department, Jeddah Municipality," 24-Feb-2013.

[5] T. Kersten, K. Mechelke, M. Lindstaedt, and H. Sternberg, "Geometric accuracy investigations of the latest terrestrial laser scanning systems," Proc Integrating Gener. FIG Work. Week, 2008.

[6] T. Abmayr, F. Härtl, M. Reinköster, and C. Fröhlich, "Terrestrial laser scanning-applications in cultural heritage conservation and civil engineering," in Proceedings of the ISPRS Working Group V/4 Workshop 3D-ARCH 2005, Virtual Reconstruction and Visualization of Complex Architectures, International Archives of Photogrammetry, Remote Sensing and Spatial Information Sciences, MestreVenice, 2005.

[7] C. Eastman, P. Teicholz, R. Sacks, and K. Liston, BIM handbook: A guide to building information modeling for owners, managers, designers, engineers and contractors. Wiley. com, 2011.

[8] T. Fussel, S. Beazley, G. Aranda-Mena, A. Chevez, J. Crawford, B. Succar, R. Drogemuller, S. Gard, and D. Nielsen, "National guidelines for digital modelling," 2009.

[9] D. Oreni, "From 3D Content Models to HBIM for Conservation and Management of Built Heritage," in Computational Science and Its Applications - ICCSA 2013, vol. 7974, Springer Berlin Heidelberg, 2013, pp. 344-357.

[10] A. Baik, A. Alitany, J. Boehm, and S. Robson, "Jeddah Historical Building Information Modelling' JHBIM'-Object Library," 2014.

[11] M. Murphy, "Historic Building Information Modelling (HBIM) For Recording and Documenting Classical Architecture in Dublin 1700 to 1830," Doctor of Philosophy thesis, Trinity College Dublin, Dublin, 2012.

[12] S. Al-Kheder, Y. Al-Shawabkeh, and N. Haala, "Developing a documentation system for desert palaces in Jordan using 3D laser scanning and digital photogrammetry," J. Archaeol. Sci., vol. 36, no. 2, pp. 537$546,2009$. 